\title{
The Effect of Various Additives to Local Anesthetics on the Duration of Analgesia of Supraclavicular Brachial Plexus Block
}

\author{
Mohyiedin Hassan*, Kamelia A Abaza, Ekram F Sayouh and Al Shaimaa A Kamel \\ Department of Anesthesia and Surgical Intensive Care, Zagazig University, Egypt
}

Submission: June 03, 2019; Published: June 20, 2019

*Corresponding author: Mohyiedin Hassan, Department of Anesthesia and Surgical Intensive Care, Zagazig University, Egypt

\begin{abstract}
Background: We compared the effect of adding Dexmedetomidine, Magnesium Sulphate or Ketamine to local anesthetics in ultrasound guided supraclavicular brachial plexus block. Duration of analgesia provided by the block is the primary outcome.

Patient and Methods: sixty patients posted for upper limb surgeries were enrolled for a comparative randomized prospective controlled clinical study. Patients were divided into four groups, the Dexmedetomidine group (D), the Magnesium group (M), the Ketamine group (K) and the Control group (C). In group D ( $\mathrm{n}=15)$, that administered $24 \mathrm{ml}$ volume of local anesthetics (Lidocaine $2 \%+$ Bupivacaine $0.5 \% 1: 1$ mixture) +100 mcg Dexmedetomidine in $1 \mathrm{ml}$ volume.; in group $\mathrm{M}(\mathrm{n}=15)$, administered $24 \mathrm{ml}$ volume of local anesthetics (Lidocaine $2 \%+$ Bupivicaine $0.5 \%$ $1: 1$ mixture)+Magnesium Sulphate $100 \mathrm{mg}$ in $1 \mathrm{ml}$ volume.; in group $\mathrm{K}(\mathrm{n}=15)$, administered $24 \mathrm{ml}$ volume of local anesthetics (Lidocaine $2 \%$ +Bupivicaine $0.5 \% 1: 1$ mixture)+ Ketamine $50 \mathrm{mg}$ in $1 \mathrm{ml}$ volume, while the control group (C) ( $\mathrm{n}=15)$, administered $24 \mathrm{ml}$ volume of local anesthetics (Lidocaine 2\% +Bupivicaine $0.5 \% 1: 1$ mixture) $+1 \mathrm{ml}$ volume normal saline $0.9 \% \mathrm{NaCl}$. The time between the complete sensory block and the first analgesic requested by the patient was assessed.
\end{abstract}

Results: Demographic data and surgical characteristics were comparable in all groups. The D group showed delay in onset for first call for analgesia $(900 \pm 60.9 \mathrm{~min})$ while $\mathrm{M}$ and $\mathrm{K}$ groups results were $(600 \pm 33.4 \mathrm{~min})$ and $(350 \pm 17.4 \mathrm{~min})$ respectively, all of the group's results were statistically significant than the control group result ( $260 \pm 14.3 \mathrm{~min})$.

Conclusion: There was statistically significant increase in the duration of analgesia in all groups more than the control. Patients who received dexmedetomidine were the last to require analgesia, then magnesium followed by ketamine.

Keywords: Supraclavicular; Brachial plexus; Upper limb; Ultrasound; Magnesium; Dexmedetomidine

\section{Introduction}

Local anesthetics alone for supraclavicular brachial plexus block provide good operative conditions but have shorter duration of postoperative analgesia. Hence, various adjuvants were added to local anesthetics in brachial plexus block to achieve quick, dense, and prolonged block [1].

Magnesium is one of the most plentiful cations in the body. Magnesium is necessary for the presynaptic release of acetylcholine from nerve endings and may produce effects like calcium-entry-blocking drugs. Anti-nociceptive effects of Magnesium are due to regulation of calcium influx into the cell and antagonism of the N-methyl D-aspartate (NMDA) receptors [2].

Dexmedetomidine is highly selective, specific and potent $\alpha 2$ adrenergic agonist having analgesic, sedative, antihypertensive, and anesthetic sparing effects when used in systemic route.
Adding Dexmedetomidine to local anesthetics during peripheral nerve blockade and regional anesthesia procedures may also prove efficacious for the surgical patients. Dexmedetomidine has also shown to prolong the duration of the block and postoperative analgesia when added to local anesthetic in various regional blocks [3].

Ketamine is a well-known anesthetic agent with potent local effect on peripheral nerves. This local effect of ketamine is most probably by blocking the voltage operated sodium channels. The effect of ketamine on (NMDA) antagonism abolishes peripheral afferent noxious stimulation [4].

\section{Materials and Methods}

After the approval of the Zagazig University Institutional Review Board, patients were explained about the drugs and the approach, and only those who gave wellful written informed 
consent were included in the study. ASA physical status I and II patients, 18-60 years undergoing unilateral upper limb surgeries below level of the shoulder under supraclavicular brachial plexus block were enrolled in a randomized prospective controlled clinical study.

Exclusion criteria were patients who refused to be included, with peripheral neuropathy of the upper limb, infection at the injection site, altered mental status or had history of allergy to local anesthetics. Also excluded were patients with coagulopathy or planned for receiving general anesthesia at the same operation for any cause as (bone graft, skin graft, etc.) or main site of the surgery is the medial side of the arm at axilla level (T2 distribution).

\section{Sample size and randomization}

Assuming that mean + SD of duration of sensory block in both Dexmedetomidine and Ketamine groups is $(413.97+238.5$ Vs $227+135$ respectively) [5]. So, sample size was calculated by open Epi to be 60 cases in 4 groups ( 15 cases in each group) with confidence level $95 \%$ and power of test is $80 \%$. A computergenerated randomization table divided patient into 4 equal groups randomly allocated patients into four groups.

Dexmedetomidine group(D) $(\mathrm{n}=15)$ received $24 \mathrm{ml}$ volume of local anesthetics (Lidocaine 2\% + Bupivacaine 0.5\% 1:1 mixture) +100 mcg Dexmedetomidine in $1 \mathrm{ml}$ volume.; Magnesium group $\mathrm{M}$ $(\mathrm{n}=15)$, administer $24 \mathrm{ml}$ volume of local anesthetics (Lidocaine $2 \%+$ Bupivicaine 0.5\% 1:1 mixture)+Magnesium Sulphate $100 \mathrm{mg}$ in $1 \mathrm{ml}$ volume.; in group $\mathrm{K}(\mathrm{n}=15)$, administered $24 \mathrm{ml}$ volume of local anesthetics (Lidocaine 2\% + Bupivicaine $0.5 \% 1: 1$ mixture)+ Ketamine $50 \mathrm{mg}$ in $1 \mathrm{ml}$ volume, while the control group (C) ( $\mathrm{n}=15$ ), administered $24 \mathrm{ml}$ volume of local anesthetics (Lidocaine $2 \%+$ Bupivicaine $0.5 \%$ 1:1 mixture) $+1 \mathrm{ml}$ volume normal saline $0.9 \% \mathrm{NaCl}$. were given for supraclavicular brachial plexus block using the ultrasound guidance.

\section{Technique}

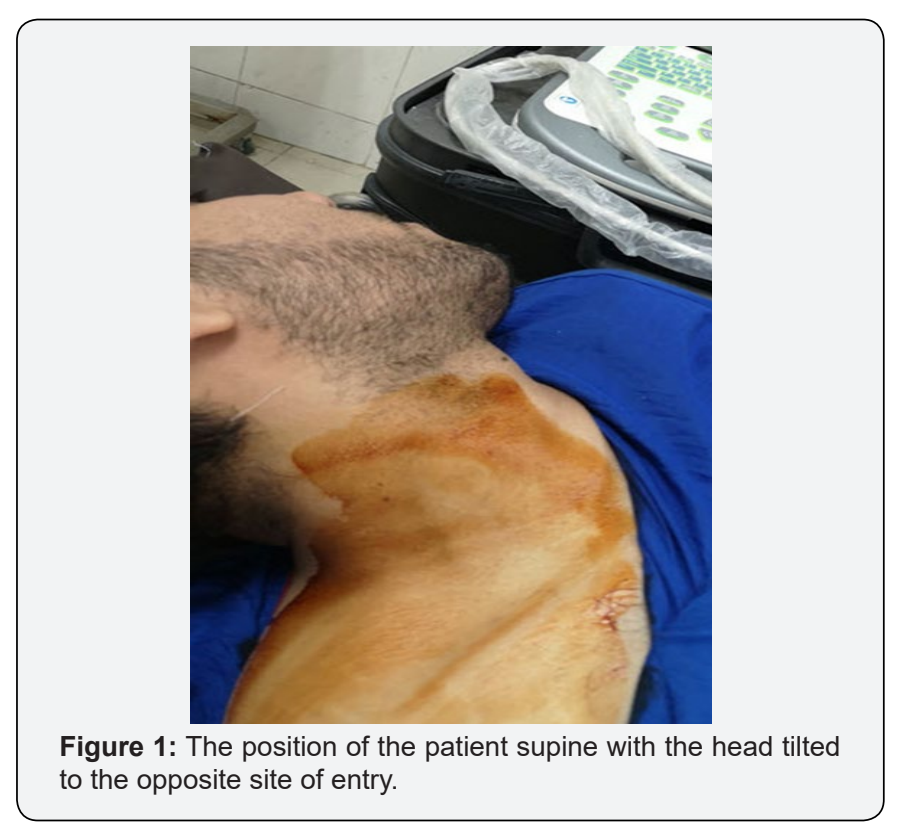

In the operating room, an intravenous line was secured and standard monitoring (Electrocardiography, Pulse Oximetry and non-invasive blood pressure) were applied to all the patients. The patients were administered brachial plexus block by supraclavicular route with the patient in the proper position (supine with the head tilted to the opposite site) (Figure 1), the skin was disinfected and the US machine transducer was positioned in the transverse plane immediately superior to the clavicle at approximately its midpoint. The transducer was manipulated to obtain a cross-sectional view of the subclavian artery. The brachial plexus is seen as a collection of hypoechoic oval structures lateral and superficial to the artery. The spread of injected drug was observed in real time to achieve a satisfactory spread of the drug around the brachial plexus (Figure 2).

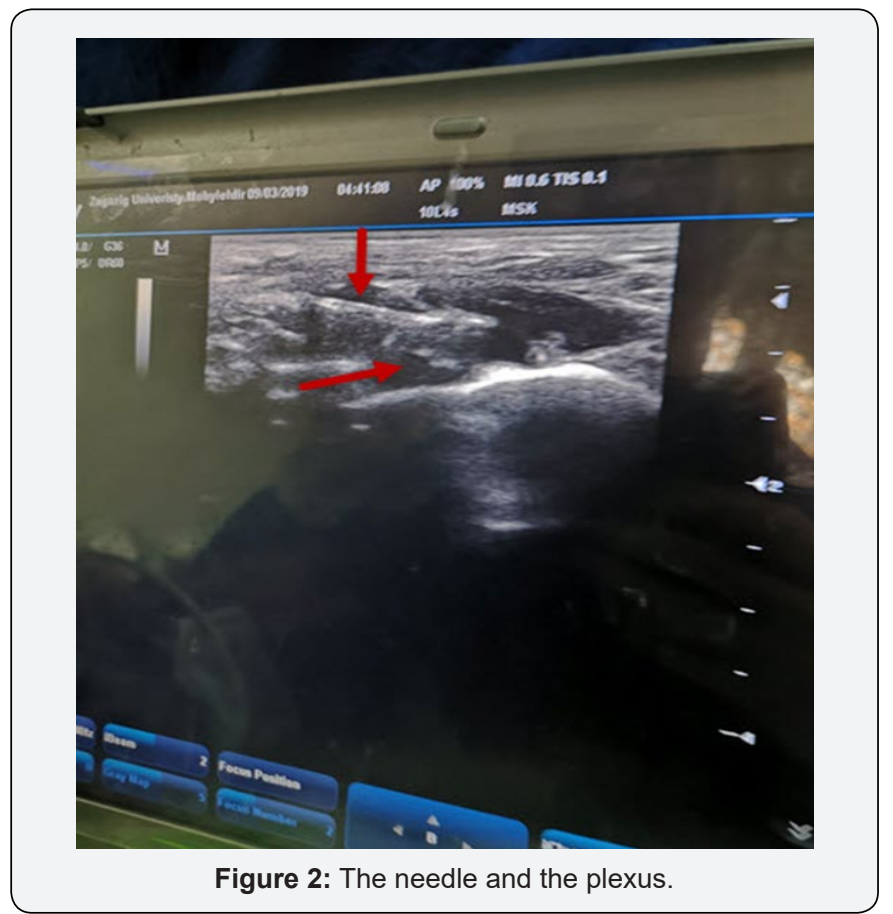

\section{Data Collection}

Duration of analgesia (DOA): the time between the complete sensory block and the first analgesic request by the patient (complete sensory block was considered when there was complete loss of sensation to pin prick at the dermatomes corresponding to median nerve, radial nerve, ulnar nerve and muscle-cutaneous nerve). Pain was assessed using the Visual Analogue Scale (VAS score) after explaining it to the patient as an instrument used to quantify a subjective experience, such as the intensity of pain. A commonly used visual analog scale is a $10-\mathrm{cm}$ line labelled with "worst pain imaginable" on the right border and "no pain" on the left border (Figure 2). The patient was instructed to make a mark along the line to represent the intensity of pain currently being experienced. AS score was assessed every hour in the first 4 hours after the end of the operation then every 4 hours for 24 hour and injection of $25 \mathrm{mcg}$ Fentanyl (rescue analgesic) was given bolus (IV) when VAS $\geq 3$. The data was compiled and subjected to statistical analysis using Statistical Package for Social Sciences (SPSS), version15. 
Demographic and hemodynamic data were subjected to Student's t-test and for statistical analysis of the duration of the analgesia unpaired t-test was applied and reconfirmed with the Wilcoxon W and Mann-Whitney U tests. P-value $<0.05$ was considered as statistically significant and $\mathrm{P}<0.001$ as highly significant.

\section{Results}

The demographic data and ASA characteristics were comparable in both groups (Table 1). Our results revealed that Table 1: The demographic data of the studied groups.

\begin{tabular}{|c|c|c|c|c|c|c|c|c|c|c|}
\hline Variable & \multicolumn{2}{|c|}{$\begin{array}{c}\text { Saline } \\
\text { Group(C) }(n=15)\end{array}$} & \multicolumn{2}{|c|}{$\begin{array}{l}\text { Dexmedetomidine } \\
\text { Group(D) }(n=15)\end{array}$} & \multicolumn{2}{|c|}{$\begin{array}{l}\text { Magnesium Sulphate } \\
\text { Group(M) }(n=15)\end{array}$} & \multicolumn{2}{|c|}{$\begin{array}{c}\text { Ketamine } \\
\text { Group }(K)(n=15) \\
\end{array}$} & $\mathbf{F}$ & $\mathbf{P}$ \\
\hline \multicolumn{11}{|l|}{ Age(years) } \\
\hline Mean \pm SD & \multicolumn{2}{|c|}{$35.5 \pm 2.4$} & \multicolumn{2}{|c|}{$36.2 \pm 3.5$} & \multicolumn{2}{|c|}{$36.8 \pm 2.8$} & \multicolumn{2}{|c|}{$35.3 \pm 3.1$} & \multirow[b]{2}{*}{0.795} & 0.502 \\
\hline \multirow[t]{2}{*}{ Range } & \multicolumn{2}{|c|}{$30-37$} & \multicolumn{2}{|c|}{$29-41$} & \multicolumn{2}{|c|}{$30-44$} & \multicolumn{2}{|c|}{$28-41$} & & (NS) \\
\hline & No. & $\%$ & No. & $\%$ & No. & $\%$ & No. & $\%$ & $\chi^{2}$ & $\mathbf{P}$ \\
\hline \multicolumn{11}{|l|}{ Gender } \\
\hline Female & 7 & 46.7 & 6 & 40 & 8 & 53.3 & 5 & 33.3 & \multirow{2}{*}{1.357} & 0.715 \\
\hline Male & 8 & 53.3 & 9 & 60 & 7 & 46.7 & 10 & 66.7 & & (NS) \\
\hline \multicolumn{11}{|l|}{ ASA } \\
\hline I & 12 & 80 & 11 & 73.3 & 10 & 66.7 & 13 & 86.7 & \multirow[b]{2}{*}{1.863} & 0.601 \\
\hline II & 3 & 20 & 4 & 26.7 & 5 & 33.3 & 2 & 13.3 & & (NS) \\
\hline
\end{tabular}

T test: Independent sample t test,

NS: Non-significant difference $(p>0.05)$,

Data is expressed as Mean $\pm S D$, Number (percentage).

Table 2: The duration of analgesia.

\begin{tabular}{|c|c|c|c|c|c|c|}
\hline Variable & $\begin{array}{c}\text { C group } \\
(n=15)\end{array}$ & $\begin{array}{c}\text { D group } \\
(n=15)\end{array}$ & $\begin{array}{c}\text { M group } \\
(n=15)\end{array}$ & $\begin{array}{c}\text { K group } \\
(n=15)\end{array}$ & $\mathbf{F}$ & $\mathbf{P}$ \\
\hline The time of first requirement for analgesia ( $\mathrm{min}$ ) & & & & & & $<0.001^{* *}(\mathrm{HS})$ \\
\hline Mean \pm SD & $260 \pm 14.3$ & $900 \pm 60.9$ & $600 \pm 33.4$ & $350 \pm 17.4$ & 926 & \\
\hline Range & $240-280$ & $700-1500$ & $400-710$ & $270-420$ & & \\
\hline
\end{tabular}

**: Highly significant difference $(\mathrm{P}<0.001)$.

Data are expressed as mean + standard deviation.

\section{Discussion}

This study was done to compare the effect of administration additives (namely Dexmedetomidine, Magnesium sulphate and ketamine) individually to local anesthetics mixture in US guided supraclavicular brachial plexus block, it found that adding these additives provide more longer duration of analgesia to the patient in comparison to the control group .The superior effect was to Dexmedetomidine then Magnesium Sulphate followed by Ketamine.

Besides its central-mediated analgesia [6], the mechanism by which Dexmedetomidine enhances the quality of regional anesthesia when used as an adjuvant to LAs can be explained by two peripheral mechanisms [7-9]. The first is the vasoconstrictor effect around the site of injection which leads to delay of the absorption of the LAs and prolong the duration of the LAs effect. The second mechanism is the direct action of Dexmedetomidine on the activity of PN. Dexmedetomidine may inhibit the compound there were highly statistically significant differences between the studied groups as regarding timing of first requirement for analgesia. The D group showed statistically significant delay in onset for first call for analgesia $(900 \pm 60.9 \mathrm{~min})$ than other groups. $\mathrm{M}$ group also showed statistically significant delay in onset for first call for analgesia $(600 \pm 33.4 \mathrm{~min})$ than $\mathrm{K}$ group and $\mathrm{C}$ group. $\mathrm{K}$ group showed statistically significant delay in onset for first call for analgesia $(350 \pm 17.4 \mathrm{~min})$ and then C group (260 $\pm 14.3 \mathrm{~min})$

(Table 2). 
The effect of analgesia by ketamine is prolonged when administered with the local anesthetic agents due to the higher concentration of ketamine in the pre-neural fat than in the systemic circulation. It exerts the effect on neuronal transmission by blocking the $\mathrm{Na}+\mathrm{K}+$ ion gates at the peripheral nerves [13].

The superiority of dex over Magnesium in our study is in accordance with Elyazed \& Mogahed [14] in their comparative study between Magnesium Sulfate and Dexmedetomidine as an Adjuvant to $0.5 \%$ Ropivacaine in Infraclavicular Brachial Plexus Block [14]. Also, our study`s results goes with Mohamed \& Genidyin [15] their study Magnesium sulphate versus Dexmedetomidine as an adjuvant to local anesthetic mixture in peribulbar anesthesia [15].

Consistent with the current study results also, Kassem et al. [16] showed in a comparative study between Dexmedetomidine and Magnesium addition to LA s, but for peribulbar block their result also coincided with the superiority of Dexmedetomidine over Magnesium. The onset of block was more rapid in the dexmedetomidine group than the magnesium sulphate group [16] Overall, these findings of dexmedetomidine are in accordance with findings reported by Ammar \& Mahmoud [17], Esmaoglu et al. [18] \& Gandhi et al. [19].

While our results for magnesium group concided with Reddy et al. [20] \& Mathur A \& Singh LP [21] who attributed the prolonged duration of analgesia either to reducing post synaptic activity of slow conducting unmyelinated C-fibers [20,21]. Regarding ketamine the results come with Lashgarinia et al. [22] who in line with the ideas of Tverskoy et al. [23] who showed found the longlasting analgesic effect of ketamine on postoperative pain could be explained by the effect of ketamine on the inhibition of central sensitization.

\section{Conclusion}

There was statistically significant increase in the duration of analgesia when adding additive to LAs mixture for supraclavicular brachial plexus block in all groups more than the control. Patients who received dexmedetomidine were the last to require analgesia, then magnesium followed by ketamine.

\section{References}

1. Kirksey MA, Haskins SC, Cheng J, Liu SS (2015) Local Anesthetic Peripheral Nerve Block Adjuvants for Prolongation of Analgesia: A Systematic Qualitative Review. PLoS One 10(9): e0137312.

2. Sirvinskas E, Laurinaitis R (2002) Use of Magnesium sulfate in anesthesiology. Medicina (Kaunas) 38(7): 695-698.

3. KettnerSC (2013) Dexmedetomidine as adjuvant for peripheral nerve blocks. Br J Anaesth 111(1): 123.

4. Martindale SJ, Dix P, Stoddart PA (2004) Double-blind randomized controlled trial of caudal versus intravenous S+ketamine for supplementation of caudal analgesia in children. Br J Anaesth 92(3): 344-347.

5. Sabra MM, Fadlallah BI, Saleh AA, Alkoneyty A, Alkelany H (2014) Dexmedetomidine versus Ketamine as An Adjuvant in Ultrasound-Guided Axillary Brachial Plexus Block. Al Azhar Assiut Medical Journal 12(4): 110-126.
6. Swami SS, Keniya VM, Ladi SD, Rao R (2012) Comparison of Dexmedetomidine and clonidine ( $\alpha 2$ agonist drugs) as an adjuvant to local anaesthesia in supraclavicular brachial plexus block: A randomized double-blind prospective study. Indian Journal of Anesthesia 56(3): 243-249.

7. Guo TZ, Jiang JY, Buttermann AE, Maze M (1996) Dexmedetomidine injection into the locus ceruleus produces antinociception. Anesthesiology 84(4): 873-881.

8. Talke P, Lobo E, Brown R (2003) Systemically administered alpha2-agonist-induced peripheral vasoconstriction in humans. Anesthesiology 99(1): 65-70.

9. Kosugi T, Mizuta K, Fujita T, Nakashima M, Kumamoto E (2010) High concentrations of Dexmedetomidine inhibit compound action potentials in frog sciatic nerves without alpha (2) adrenoceptor activation. Br J Pharmacol 160(7): 1662-1676.

10. Lee AR, Yi HW, Chung IS, Ko JS, Ahn HJ, et al. (2012) Magnesium added to bupivacaine prolongs the duration of analgesia after interscalene nerve block. Can J Anaesth 59(1): 21-27.

11. Mukherjee K, Das A, Basunia SR, Dutta S, Mandal P, et al. (2014) Evaluation of Magnesium as an adjuvant in Ropivacaine-induced supraclavicular brachial plexus block: A prospective, double-blinded randomized controlled study. Journal of Research in Pharmacy Practice 3(4): 123-129.

12. Haghighi M, Soleymanha M, Sedighinejad A, Mirbolook A, Naderi Nabi B, et al. (2015) The effect of Magnesium sulfate on motor and sensory axillary plexus blockade. Anesthesiology and pain medicine 5(1): e21943.

13. Ivani G, Vercellino C, Tonetti F (2003) Ketamine: a new look to an old drug. Minerva Anesthesiol 69(5): 468-471.

14. Elyazed M, Mogahed MM (2018) Comparison of Magnesium Sulfate and Dexmedetomidine as an Adjuvant to $0.5 \%$ Ropivacaine in Infraclavicular Brachial Plexus Block. Anesthesia essays and researches 12(1): 109-115.

15. Mohamed AZE, Genidy MM (2017) Magnesium sulphate versus Dexmedetomidine as an adjuvant to local anasthetic mixture in peribulbar anesthesia. Egyptian Journal of Anaesthesia 33(4): 375-380.

16. Kassem OAH, ELgarhy AMM, Salim MG (2018) Magnesium sulphate versus Dexmedetomidine as adjuvants for local anesthetics in peribulbar block for eye surgeries: Clinical comparative study. The Egyptian Journal of Hospital Medicine 72(4): 4308-4312.

17. Ammar AS, Mahmoud KM (2012) Ultrasound-guided single injection infraclavicular brachial plexus block using bupivacaine alone or combined with dexmedetomidine for pain control in upper limb surgery: a prospective randomized controlled trial. Saudi J Anaesth 6(2): 109114.

18. Esmaoglu A, Yegenoglu F, Akin A, Turk C (2010) Dexmedetomidine added to levobupivacaine prolongs axillary brachial plexus block Anesth Analg 111(6): 1548-1551.

19. Gandhi R, Shah A, Patel I (2012) Use of dexmedetomidine along with bupivacaine for brachial plexus block. National J Med Res 2(1): 67-69.

20. Reddy KN, Sachidanand RS, Rao BS, Kumar DP, Srinath MM (2015) Comparative study of ropivacaine $\mathrm{v} / \mathrm{s}$ ropivacaine with magnesium sulphate for brachial plexus block. Journal of Evidence Based Medicine and Healthcare (JEBMH) 2(39): 6387-6398.

21. Mathur A, Singh LP (2018) A comparative study to evaluate the effect of magnesium sulphate and normal saline as an adjuvant to $0.5 \%$ ropivacaine on sensory, motor and postoperative analgesia in supraclavicular brachial plexus blockade. Global Journal for Research Analysis 7(4): 57-59.

22. Lashgarinia M, Naghibi K, Honarmand A, Safavi M, Khazaei M (2014) 
Effect of ketamine as an adjuvant in ultrasound-guided supraclavicular brachial plexus block: A double-blind randomized clinical trial study. Adv Biomed Res 3: 232.
23. Tverskoy M, Oren M, Vaskovich M, Dashkovsky I, Kissin I (1996) Ketamine enhances local anesthetic and analgesic effects of bupivacaine by peripheral mechanism: A study in postoperative patients. Neurosci Lett 215(1): 5-8.

\section{Your next submission with Juniper Publishers} will reach you the below assets

- Quality Editorial service

- Swift Peer Review

- Reprints availability

- E-prints Service

- Manuscript Podcast for convenient understanding

- Global attainment for your research

- Manuscript accessibility in different formats

( Pdf, E-pub, Full Text, Audio)

- Unceasing customer service

Track the below URL for one-step submission https://juniperpublishers.com/online-submission.php 